\title{
BMJ Open Omega-3 polyunsaturated fatty acid intake norms and preterm birth rate: a cross-sectional analysis of 184 countries
}

\author{
Timothy H Ciesielski, , ${ }^{1,3}$ Jacquelaine Bartlett, ${ }^{1,3}$ Scott M Williams ${ }^{1,3}$
}

To cite: Ciesielski TH, Bartlett J, Williams SM. Omega-3 polyunsaturated fatty acid intake norms and preterm birth rate: a cross-sectional analysis of 184 countries. BMJ Open 2019;9:e027249. doi:10.1136/ bmjopen-2018-027249

- Prepublication history and additional material for this paper are available online. To view these files, please visit the journal online (http://dx.doi. org/10.1136/bmjopen-2018027249).

Received 12 October 2018 Revised 18 February 2019 Accepted 21 February 2019

Check for updates

(C) Author(s) (or their employer(s)) 2019. Re-use permitted under CC BY-NC. No commercial re-use. See rights and permissions. Published by BMJ.

${ }^{1}$ Department of Population and Quantitative Health Sciences,

Case Western Reserve

University, Cleveland, Ohio, USA

${ }^{2}$ Ronin Institute, Montclair, New

Jersey, USA

${ }^{3}$ The Institute for Quantitative

Biomedical Sciences, Dartmouth College, Hanover, New Hampshire, USA

Correspondence to Dr Timothy H Ciesielski; timothyhciesielski@gmail.com

\section{ABSTRACT}

Background The preponderance of evidence now indicates that elevated long-chain omega-3 polyunsaturated fatty acid (LC omega-3 PUFA) intake is often associated with reduced risk of preterm birth (PTB). This conclusion is based on recent meta-analyses that include several studies that reported null findings. We probed the reasons for this heterogeneity across studies and its implications for PTB prevention using country-level data.

Methods We analysed the relationship between national PTB rates ( $<37$ weeks of gestation) and omega-3 PUFA intake norms from 184 countries for the year 2010. To estimate the total LC omega-3 PUFA levels (eicosapentaenoic acid [EPA]/docosahexaenoic acid $[\mathrm{DHA}]$ ) that these norms produce we utilised a metric that accounts for (1) seafood-based omega-3 intake (EPA/DHA) and (2) plant-based omega-3 intake (alpha-linolenic acid [ALA]), $\sim 20 \%$ of which is converted to EPA/DHA in vivo. We then assessed the shape of the omega-3-PTB relationship with a penalised spline and conducted linear regression analyses within the linear sections of the relationship. Results Penalised spline analyses indicated that PTB rates decrease linearly with increasing omega-3 levels up to $\sim 600 \mathrm{mg} /$ day. Income-adjusted linear regression analysis among the countries in this exposure range indicated that the number of PTBs per 100 live births decreases by 1.5 ( $95 \% \mathrm{Cl} 2.8$ to 0.3$)$ for each $1 \mathrm{SD}$ increase in omega-3 intake norms ( $383 \mathrm{mg} /$ day). Conclusions Taken with prior evidence for a causal association on the individual level, our findings indicate that omega-3 PUFA deficiency may be a widespread contributing factor in PTB risk. Consideration of baseline omega-3 PUFA levels is critical in the design of future interventions.

\section{INTRODUCTION}

Preterm birth (PTB), or pregnancy lasting $<37$ weeks, is a common obstetrical problem associated with a number of immediate and lifelong health problems, including neonatal death, acute and chronic lung disease, brain injuries and neurodevelopmental problems. ${ }^{12}$ These outcomes have enormous economic and public health impacts, ${ }^{1-5}$ providing strong motivation to understand modifiable processes that mediate risk. Here,

\section{Strengths and limitations of this study}

This study helps to explain why it took over 33 years to confirm that elevated long-chain omega-3 polyunsaturated fatty acid (LC omega-3 PUFA) intakes are associated with reduced risk of preterm birth (PTB).

- Our analysis of country-level omega-3 intake norms and PTB rates illuminates three critical factors that were only sporadically addressed in the prior studies: (1) baseline intake rates, (2) alternative dietary sources of LC omega-3 PUFA and (3) the possibility of a threshold for sufficient intake.

- The cross-sectional ecological design of this study means that it cannot provide strong evidence for a causal association on the level of the individual, but this evidence already exists, and our study provides essential contextual information.

- Increasing LC omega-3 PUFA intake norms may lower PTB rates in 157 of the 184 countries studied.

we aim to better illuminate an emerging nutritional factor, long-chain omega-3 polyunsaturated fatty acid (LC omega-3 PUFA), the role of which has been obscured by the heterogeneity of unmeasured baseline intakes. To achieve this aim, we use country-level PTB rates and dietary fat intake estimates to (1) characterise the potential worldwide impact of this dietary factor and (2) reassess conclusions drawn from the prior literature.

Thirty years ago, landmark epidemiological observations from the Faroe Islands indicated that high dietary intake of fish oils (oils that are rich in LC omega-3 PUFAs) associated with longer gestation and improved fetal growth. ${ }^{67}$ Since then, follow-up studies including epidemiological investigations, laboratory experiments and randomised controlled trials attempted to test these associations. ${ }^{8-28}$ Initially, this work failed to definitively validate the fish oil hypothesis. In retrospect, this uncertainty should not be surprising given the complexity of the pathophysiology and the prior analytic issues that are only evident in hindsight (online supplementary 
table S1 and S2). However, three decades later consensus is finally developing, sufficient omega 3 PUFA intake increases gestational length, prevents PTB and increases birth weight (perhaps by extending gestation) ${ }^{29-33}$ Even more importantly, having adequate maternal LC omega-3 PUFA stores appears to result in healthier offspring (eg, improved neurocognitive development, decreased likelihood of atopy/allergy, ${ }^{34-36}$ and perhaps, decreased risk of stillbirth, infant death and Neonatal Intensive Care Unit $\operatorname{admission}^{31}$ ).

Here, we present an ecological analysis of PTB rates and country-level omega-3 PUFA intakes in 184 countries to characterise their relationship globally. Our analyses corroborate an emerging consensus in the individual level studies, and can inform the design of future interventions, including nutritional recommendations, fortification strategies, food system changes and primary care practices. The results also indicate that omega-3 intake prior to intervention can affect trial success, and because consumption varies across countries, prevention strategies may need to be context dependent.

\section{METHODS}

We obtained, from published data, country-level estimates of PTB rates ${ }^{1}$ and fatty acid intakes ${ }^{3738}$ in 184 countries for the year 2010, with methods as described elsewhere. ${ }^{137}$ These 184 countries were selected because they had data on both exposure (omega-3 intakes) and outcome (РTB rates). Briefly, the PTB rate data were estimated from four primary sources: (1) reproductive health surveys, (2) national statistical offices and registries, (3) published papers identified in a systematic literature review and (4) unpublished data from the Child Health Epidemiology Reference Group. ${ }^{1}$ PTB was defined as delivery prior to 37 weeks of gestation, and the data exclusion criteria and handling protocols are outlined in Blencowe et al. ${ }^{1}$ The authors put extensive effort into vetting, integrating and standardising the heterogeneous source data, ${ }^{1}$ and here we summarise the key points as we understand them.

All primary data sources had a minimum of 50 births, and datasets were excluded if the possibility of bias from seasonal PTB rate changes could not be assessed (Blencowe et al, p2164). ${ }^{1}$ The authors utilised a twofold quality screen to exclude primary data sources that demonstrated evidence of 'poor case ascertainment'; data sources were excluded if: (1) fewer than $2 \%$ of the reported PTBs occurred before 28 weeks of gestation or (2) the PTB rate was reported to be $<3$ in 100 live births. This yielded 738 data sources, $74 \%$ of which were from developed, Latin American or Caribbean countries (note: these designations are Millennium Development Goal regions). The data from these largely developed regions were generally more dense and of higher quality than that of other regions of the world. The authors then incorporated covariate data and made two types of regression-based prediction models to estimate PTB rates for each country. Model 1 was used for the data dense countries and model
2 was used for the others. The authors used forward stepwise selection procedure to identity variables with predictive value to maintain in the models and though the two models were roughly similar, the differences between the PTB rate prediction models were not surprising (eg, mean adult female $B M I$ was included in model 1 , while malaria endemicity and female literacy rate were included in model $2)$. The final PTB rate was estimated in one of three ways depending on the limitations of the source data: (1) for the 13 countries with good vital registration data that used the standard definition of PTB, Loess regression was performed on that data, (2) for the 65 countries in the developed/data-dense regions that fell short of this ideal, prediction model 1 was used to estimate the PTB rate and (3) for the 106 countries outside of the developed/datadense regions prediction model 2 was used to estimate the PTB rate.

The fatty acid intake data were generated for the 2010 Global Burden of Diseases, Injuries, and Risk Factors (GBD) Study by the Nutrition and Chronic Diseases Expert Group (NutriCoDE). ${ }^{37} 3940$ As with the PTB rate data, the dietary information sources were diverse and extensive efforts were made to aggregate and harmonise the data for crosscountry comparisons. Micha $e t a l^{37}$ provides an overview flowchart of the survey identification process, and Micha et $a t^{40}$ has a 2000 word summary of the protocols. In short, national survey data were identified via Medline searches (outlined in the supplement ${ }^{40}$ ), but because some countries lacked official surveys, additional information was obtained from large epidemiological study cohorts, the WHO Stepwise Approach To Surveillance database, the WHO Global Infobase and other household surveys. ${ }^{37}$ The identified survey data were presented in many distinct metrics, and the original authors recalculated their estimates in uniform dietary units to facilitate crosscountry comparisons when needed. ${ }^{3740}$

A total of 266 surveys were identified and included: $27 \%$ single response dietary recall data, $14 \%$ multiple-response dietary recall data, 31\% Food Frequency Questionnaire Data and 29\% household availability/budget data. ${ }^{37}$ To account for the uncertainties associated with heterogeneous information sources and missing data, the authors used a Bayesian hierarchical imputation model to yield the mean consumption estimates. ${ }^{37}$

Seafood-based omega-3 intake was assessed as total dietary eicosapentaenoic acid (EPA) and docosahexaenoic acid (DHA) intake in $\mathrm{mg} /$ day (excluding supplements). ${ }^{40}$ Plant-based omega-3 intake was assessed as total dietary alpha-linolenic acid (ALA) intake in $\mathrm{mg} /$ day (excluding supplements) ${ }^{40}$ Country-level omega-3 intake norms were available for males and females of at least 20 years of age, and because our outcome was PTB rate, we utilised only values from females $\geq 20$ years of age.

To create a composite exposure metric that reflects both dietary sources of omega-3, we used available in vivo conversion estimates ${ }^{41}{ }^{42}$ to combine seafood-based LC omega-3 PUFA intake and plant-based omega-3 PUFA. Because adult females convert $20 \%$ of their ALA intake 
Table 1 Descriptive statistics for all countries and the subsets on either side of the $600 \mathrm{mg} /$ day threshold

\begin{tabular}{|c|c|c|c|c|c|}
\hline & Median & Mean & IQR & SD & Range \\
\hline \multicolumn{6}{|l|}{ All countries $(n=184)$} \\
\hline PTB rate* (\# PTBs per 100 live births) & 10.2 & 10.2 & $7.7-12.4$ & 3.0 & $4.1-18.1$ \\
\hline Gross National Incomeł & 2.0 & 1.6 & $1.0-2.5$ & 1.1 & $0.0-3.0$ \\
\hline \multicolumn{6}{|c|}{ Countries $<600 \mathrm{mg} /$ day estimated total LC omega-3 PUFA $(n=157)$} \\
\hline Estimated total LC omega-3 PUFA† (mg/day) & 267 & 277 & 164-369 & 134 & $45-579$ \\
\hline Gross National Incomeł & 1.0 & 1.5 & $1.0-2.0$ & 1.1 & $0.0-3.0$ \\
\hline \multicolumn{6}{|c|}{ Countries above $600 \mathrm{mg} /$ day estimated total LC omega-3 PUFA ( $\mathrm{n}=26$, Maldives excluded as an omega-3 intake outlier) } \\
\hline PTB rate* (\# PTBs per 100 live births) & 9.3 & 9.4 & $7.1-12.0$ & 2.9 & $5.5-15.5$ \\
\hline Estimated total LC omega-3 PUFA† (mg/day) & 804 & 907 & $677-959$ & 331 & 618-2012 \\
\hline
\end{tabular}

${ }^{*}$ PTB rates from Blencowe et al. ${ }^{1}$

TLC omega-3 PUFA levels based on information from Micha et $a^{37}{ }^{38}$ and the calculations described in the Methods section. $\ddagger$ Gross National Income coded as a variable with four levels using the World Bank Atlas Method ( $0=$ low income, $3=$ high income). ${ }^{1}$ LC omega-3 PUFA, long- chain omega-3 polyunsaturated fatty acid; PTB, preterm birth.

into EPA, ${ }^{41}{ }^{42}$ we created the total LG omega-3 PUFA metric as follows:

\section{Total LC omega3 PUFA $=($ plant based $\times 0.2)+$ seafood based}

This approach to exposure assessment allowed for the integration of these two distinct sources into one biologically interpretable metric that reflects the net availability of LC omega-3 PUFA.

We hypothesise that if maternal LC omega-3 PUFA body stores/blood levels are important for increasing birth weight and extending gestation, then countries where women have low omega-3 PUFA intake should have higher PTB rates. We also expect countries with high omega-3 PUFA intakes to have lower PTB rates.

Because an intake threshold may exist above which PTB rate is no longer affected, ${ }^{9} 4344$ we assessed the linearity of the omega-3-PTB relationship with a penalised spline. In short, we created a model with PTB rate as the outcome and total omega-3 PUFA intake as a smoothed exposure variable (a penalised spline). The spline was selected using a generalised cross-validation (GCV) procedure from GAM in the mgcv package in R V.3.5.0. GCV is a standardised iterative process that selects a smooth non-linear function when there is sufficient evidence of non-linearity. ${ }^{4546}$ If there is insufficient evidence of a deviation from linearity then GCV selects a linear model. This process identified a non-linear smooth function for the omega-3-PTB relationship, indicating the existence of an exposure threshold. Because the relationship appeared linear below and above this threshold, we constructed linear regression models to (1) characterise these two linear regions of the relationship and (2) identify the putative threshold.

We did not attempt to identify an omega-3 PUFA intake level that would be sufficient for a given individual, nor did we attempt to estimate individual risk of PTB associated with low omega-3 intake. These analyses simply evaluate if reductions in country-level omega-3 PUFA intake are associated with elevated PTB rates. As with many country-level analyses, we had limited covariate information, and this constrained our ability to assess for potential confounding. However, one key variable was available: country income level. Blencowe et al listed the WHO country-level income categories based on per capita Gross National Income (GNI-World Bank Atlas Method-a variable with four levels; higher rank corresponds to higher income). ${ }^{1}$ All 184 countries had available GNI data. This allowed us to build regression models that yielded crude and income-adjusted associations between omega-3 PUFA intake and PTB rate. Regression analyses and splines were conducted with R V.3.5.0 (http://www. r-project.org), and other analyses were performed with SAS V.9.4.

Because the ALA to EPA/DHA conversion rate $\left(20 \%^{41}{ }^{42}\right)$ has not been extensively characterised, and there is reason to believe that both genetic ${ }^{478}$ and nutritional factors, ${ }^{49}{ }^{50}$ could modify this rate, we also evaluated seafood-based and plant-based omega-3 as two separate independent variables. Our main analysis assumed that the conversion rate is known and constant across countries. However, the alternative approach, treating the two types of consumption as independent, adds a new assumption that we also find problematic: the biological meaning of plant omega-3 intake is not altered by seafood omega-3 intake (and vice versa). Because we know that both intakes contribute to the unmeasured exposure of interest (total LC omega-3 levels), they are difficult to interpret in isolation. Another imperfect, but useful way, to handle the uncertainty of the conversion rate is to evaluate a range of rates in a sensitivity analysis. This 
A

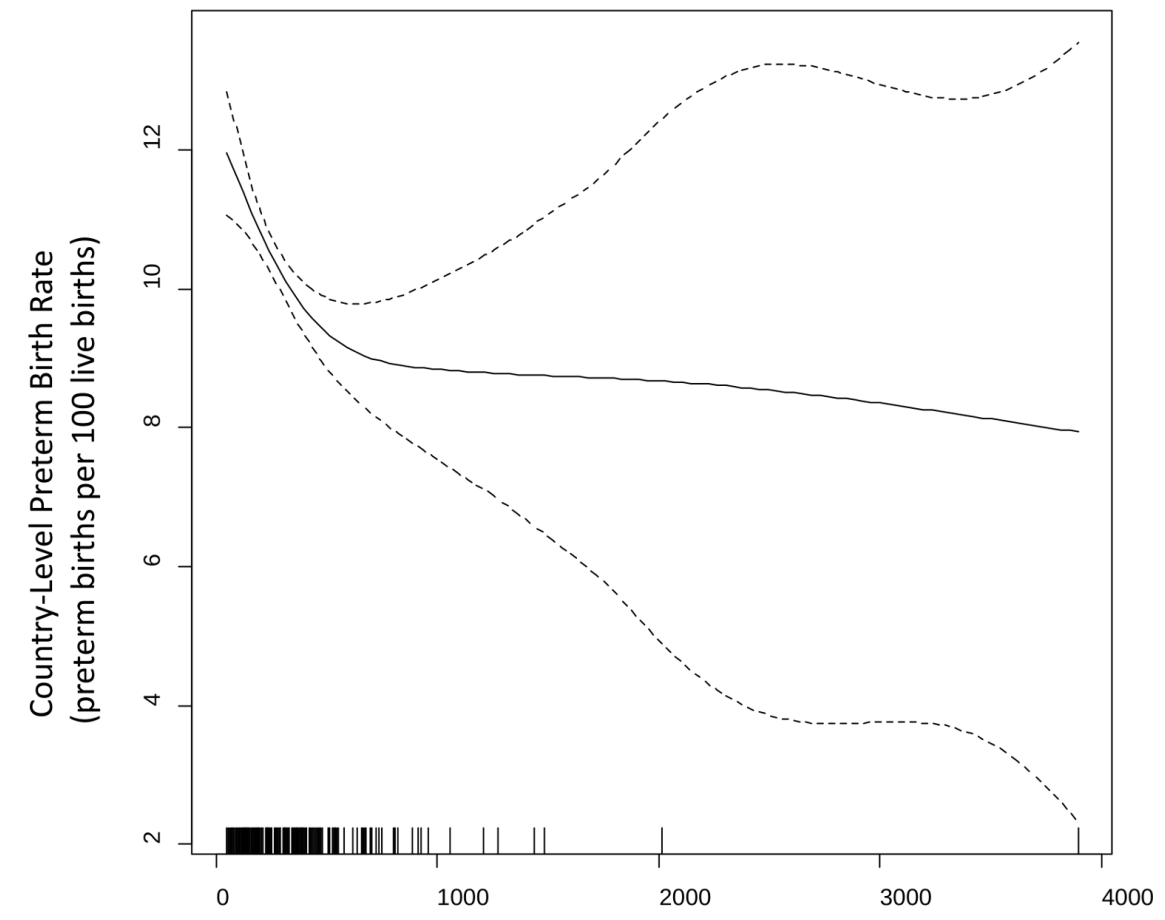

Total LC Omega-3 PUFA (mg/day)

B

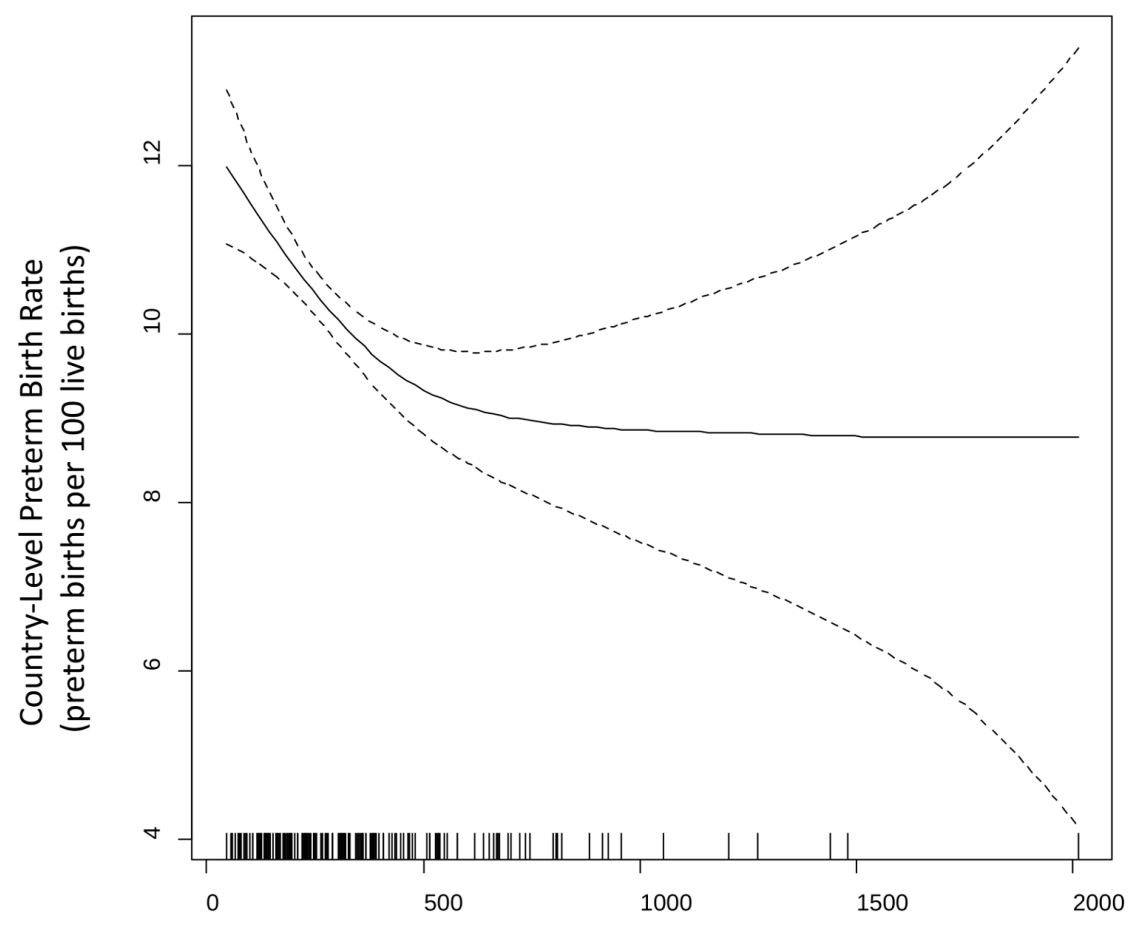

Total LC Omega-3 PUFA (mg/day)

Figure 1 Penalised spline modelling the omega-3-PTB relationship. (A) Country-level omega-3 intake norms among females are on the $\mathrm{x}$-axis and country-level preterm birth rates are on the $y$-axis. Each vertical dash below the spline on the $\mathrm{x}$-axis represents a single country, allowing the figure to convey data density throughout the exposure distribution. The shape of the spline is most certain in the areas of greatest data density. (B) Same as panel A except the Maldives were excluded, and the threshold is unchanged. LC omega-3 PUFA, long-chain omega-3 polyunsaturated fatty acid; PTB, preterm birth. 
Table 2 Results from regression models within the two linear sections of the omega-3-PTB relationship

Change in the \# of

preterm births

(per 100 live births) $95 \% \mathrm{Cl}$

\begin{tabular}{|c|c|c|}
\hline \multicolumn{3}{|c|}{$<600 \mathrm{mg} /$ day LC omega-3 PUFA $(\mathrm{n}=157)$} \\
\hline \multicolumn{3}{|l|}{ Unadjusted model } \\
\hline LC omega-3 PUFA* & -2.9 & -4.2 to -1.6 \\
\hline \multicolumn{3}{|l|}{ Adjusted model } \\
\hline LC omega-3 PUFA* & -1.5 & -2.8 to -0.3 \\
\hline Country income $\dagger$ & -1.1 & -1.6 to -0.7 \\
\hline \multicolumn{3}{|c|}{$\geq 600 \mathrm{mg} /$ day LC omega-3 PUFA $(\mathrm{n}=26) \neq$} \\
\hline \multicolumn{3}{|l|}{ Unadjusted model } \\
\hline LC omega-3 PUFA* & -0.4 & -1.8 to 0.9 \\
\hline \multicolumn{3}{|l|}{ Adjusted model } \\
\hline LC omega-3 PUFA* & 0.5 & -0.6 to 1.6 \\
\hline Country income $†$ & -2.2 & -3.1 to -1.2 \\
\hline
\end{tabular}

${ }^{*}$ Change in the number of preterm births per 100 live births associated with a 1 SD increase in LC omega-3 PUFA (383 mg/ day).

†Change in the number of preterm births per 100 live births associated with a one unit increase in GNI (a variable with four levels; higher rank corresponds to higher income). $\ddagger$ Maldives excluded as an omega-3 intake outlier. GNI, Gross National Income; LC omega-3 PUFA, long-chain omega-3 polyunsaturated fatty acid; PTB, preterm birth.

approach still assumes a constant conversion rate across countries, but it considers a variety of potential mean rates. Both of these alternative analyses are presented in the supplement.

Finally, there was an a priori reason to look for an interaction between omega-6 and omega-3 PUFA intake. Unfortunately, the available omega-6 intake data were calculated as a 'percent of total energy intake', which makes it incompatible with the omega-3 data (mg/ day) and biologically uninterpretable in this interaction context.

\section{Patient and public involvement}

This is a cross-sectional study of published country-level data. There was no involvement of patients or the public.

\section{RESULTS}

For the 184 countries with intake and PTB data for 2010, the mean PTB rate was 10.2 per 100 live births (SD: 3.0), and the mean LC omega-3 PUFA level was $310 \mathrm{mg}$ / day (SD: $383 \mathrm{mg} /$ day) (table 1 and online supplementary table S3). LC omega-3 PUFA intake was positively correlated with the country income variable (Spearman rank correlation $=0.44$, and this correlation was unchanged when an omega-3 outlier, the Maldives, was removed; online supplementary figure $\mathrm{S} 1$ ).

In the full dataset $(n=184)$, the GCV process detected evidence of non-linearity in the omega-3-PTB relationship, and selected a spline rather than a linear term to model the relationship (figure 1A). After the omega-3 intake outlier (The Maldives) was excluded, a very similar spline was obtained (figure 1B). In both panels, a threshold between 500 and $700 \mathrm{mg}$ /day of LC omega-3 PUFA was detected.

The relationship appears linear below $600 \mathrm{mg} /$ day, with PTB rates decreasing as LC omega-3 PUFA intake increases. Above $600 \mathrm{mg} /$ day, there is no significant relationship between PTB rates and omega-3 PUFA intake. The results from unadjusted and income-adjusted linear regression models above and below this threshold are presented in table 2. The Maldives were excluded as an outlier in the data above the threshold $(n=26)$, but the results were similar when this outlier was included (online supplementary table S4).

The unadjusted model for countries below $600 \mathrm{mg} /$ day intake $(n=157)$ indicates that the number of preterm births per 100 live births decreases by 2.9 (95\% CI 4.2 to 1.6 ) for each 1 SD increase in omega-3 intake norms (383 mg/ day). After adjustment for country income, the model indicates that the number of preterm births per 100 live births decreases by 1.5 (95\% CI 2.8 to 0.3$)$ for each $1 \mathrm{SD}$ increase in daily omega-3 intake. Note that the splines presented in figure 1 do not specify an exact threshold value. Six hundred milligrams per day is a visual estimate but we also examined alternative thresholds to understand the effect of changing this value (online supplementary table S5). Increasing the threshold value above $600 \mathrm{mg} /$ day increases power, as it increases the number of countries analysed, but it may violate assumption of linearity. The omega-3-PTB relationship below the threshold is significant in the unadjusted linear model regardless of the specified cut-off $(400,500,600,700,800$ or $900 \mathrm{mg} /$ day). In the adjusted model, the relationship is significant only with thresholds of 600,700 and $800 \mathrm{mg} /$ day.

In the supplementary analysis which assessed seafood-based and plant-based omega-3 PUFA as separate independent variables, the penalised splines (online supplementary figure S2) again identified putative thresholds $(600 \mathrm{mg} /$ day in the seafood-based omega-3 analysis and $3000 \mathrm{mg} /$ day in the plant-based omega-3 analysis). Additionally, the shape of the spline for the joint exposure metric was not altered by varying the ALA to EPA conversion rate assumption (online supplementary table S3), and the association with PTB rate (online supplementary table S6) was more significant when using the empirically determined conversion rate estimate $(20 \%)$. $^{4142}$

\section{DISCUSSION}

We detected a threshold in the relationship between omega-3 PUFA intakes and country-level PTB rates; country-level PTB rates decreased with increasing LC omega-3 PUFA levels up to $\sim 600 \mathrm{mg} /$ day. Above $600 \mathrm{mg} /$ day, omega-3 intake norms were not associated with country-level PTB rates. These conclusions remain after adjustment for country income. Because multiple causal 


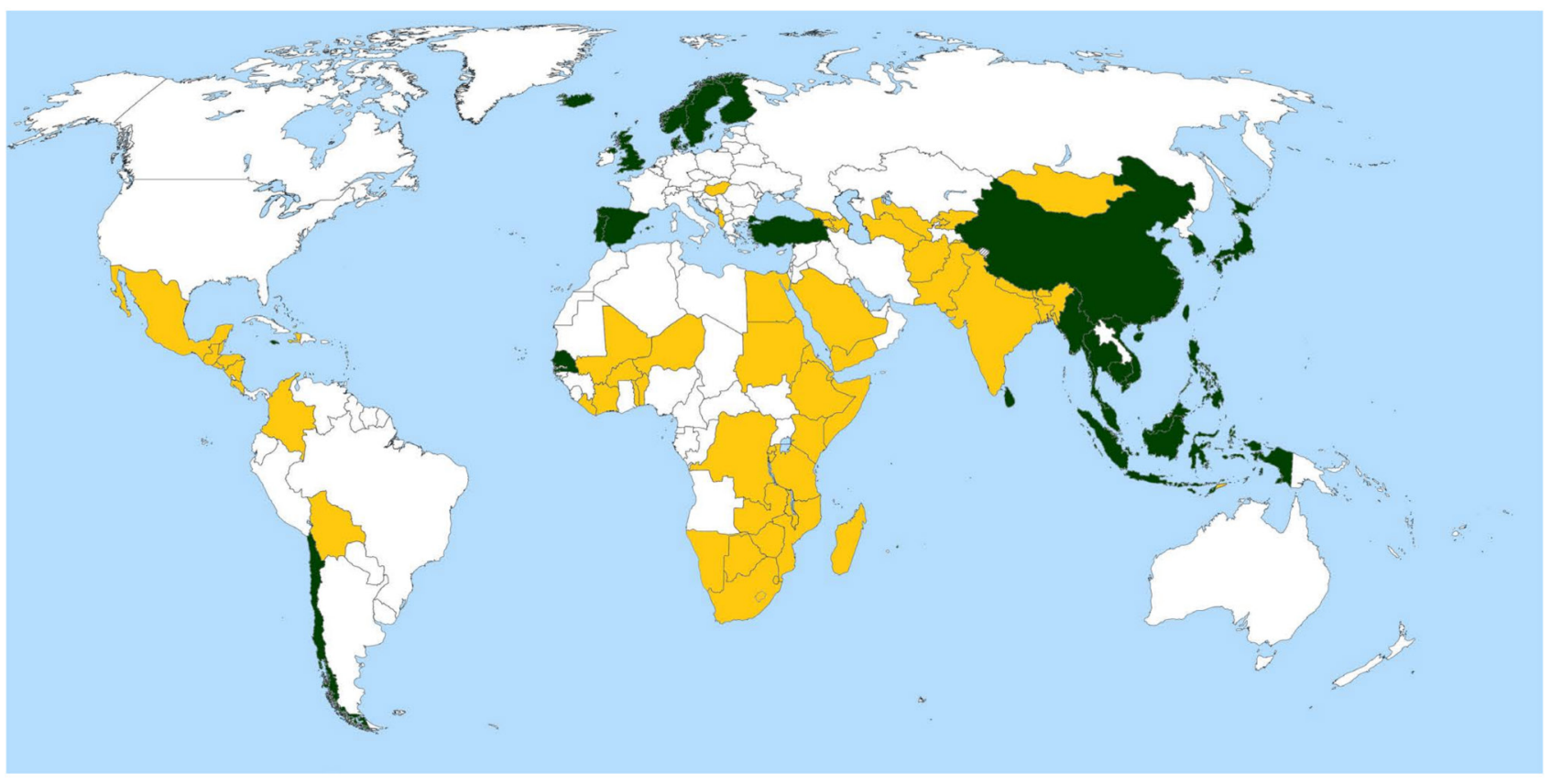

Figure 2 Countries with high and low dietary intake norms for omega-3 PUFAs among females. Countries with $>600 \mathrm{mg} /$ day LC omega-3 PUFA intake are in green, the threshold from the spline. Countries with $<217 \mathrm{mg} /$ day LC omega-3 PUFA are in gold; these countries are at least 1 SD $(383 \mathrm{mg} /$ day) below the $600 \mathrm{mg} /$ day threshold. Countries with intermediate intake levels (217$600 \mathrm{mg} /$ day) are in white. Country names and intake levels are listed in online supplementary table S3. LC omega-3 PUFA, longchain omega-3 polyunsaturated fatty acid.

structures $^{51}$ can be drawn to represent the variables in this analysis (Figure S4), it is not clear if adjustment for county income reduces bias in this context, but the association is significant in both models, and confounding from country income cannot fully explain our findings. Furthermore, it is possible that elevated country income is a proxy for omega-3 supplement use, which is not included in our estimated consumption data. If this is the case, then adjusting for country income may underestimate the omega-3-PTB association, and our income-adjusted associations would be conservative.

We acknowledge that it is difficult to assess and account for potential confounding in an ecological study. Typically, very few relevant covariates will be available in a useful form, and our study was no exception. Variables that we might want to assess would be those which (1) associate with exposure (omega-3 intake), (2) independently associate with outcome (PTB rate) and (3) are not consequences of exposure (or mediating the effect of exposure on outcome) ${ }^{51}{ }^{52}$ Any variables that we might suspect based on subject matter knowledge, and the rough criteria above, would need to be examined with directed acyclic graphs to determine if adjustment was likely to remove bias. ${ }^{51} 52$ Thus, nutrients and toxicants that are found in the same foods as omega-3 fatty acids could be of interest as potential confounders, if they are suspected to alter PTB risk. We would have assessed measures including, but not limited to, mean national: intakes of folic acid, iron and licorice, ${ }^{53}$ as well as circulating vitamin D levels, ${ }^{54}$ and chemical contaminants, ${ }^{55}$ but this information was not available.

Our results corroborate the emerging consensus of studies on the individual level: robust LC omega-3 PUFA intake is needed to maintain gestation, promote fetal growth and produce healthy offspring. ${ }^{29-31} 343556$ Furthermore, our approach addresses a key weakness in the literature by accounting for intake of plant-based precursors in the estimation of LC omega-3 PUFA levels. Adult females convert $\sim 20 \%$ of ingested plant-based omega-3 into LC omega-3 PUFA, ${ }^{41}{ }^{42}$ but earlier studies in this area did not account for plant-based omega-3 intake. This underappreciated physiology may explain some of the heterogeneity in the literature. Additionally, our observation of an intake threshold on the country level is consistent with prior reports of an intake threshold on the individual level. ${ }^{93}{ }^{44}$ LC omega-3 PUFA levels in prenatal maternal plasma are inversely related to the odds of early PTB (delivery at $<34$ weeks of gestation), but this relationship is only present when LC omega-3 PUFAs make up $<2 \%$ of the total fatty acids in maternal plasma. These results in conjunction with ours provide convergent evidence for the existence of a biological threshold with important health implications.

Although country-level analyses have limitations with regard to causal inference on the level of the individual (ie, the ecological fallacy ${ }^{57}{ }^{58}$ ), they can serve important public health functions ${ }^{57}$ and have a specific advantage in nutritional epidemiology. ${ }^{59}$ In particular, ecological 
studies are very useful when individual-level exposures, such as dietary factors, are hard to measure accurately due to extensive within-person variability. ${ }^{59}$ Overall, our country-level findings support the individual-level studies, laboratory experiments and randomised controlled trials in a distinct fashion, and this convergence allows for stronger conclusions. ${ }^{60}$ When considered along with the prior evidence ${ }^{8-2329-31}$ our results have implications for country-level prevention; omega-3 intake interventions cannot be well assessed in the absence of information on baseline dietary norms (see figure 2). Omega-3 interventions, on any level, may only be effective in the context of omega-3 insufficiency, and some of the heterogeneity in the prior literature may be due to unmeasured baseline intake.

Two meta-analyses have recently been published on the use of omega-3 supplementation for the prevention of $\mathrm{PTB}^{61}$ and recurrent PTB. ${ }^{62}$ Both reported trends indicating that omega-3 supplementation during pregnancy can prevent PTB, but the associations were not significant, and this was interpreted as a demonstration of inefficacy. However, when the characteristics of the nine papers included in these meta-analyses (seven for $\mathrm{PTB}^{963-68}$ and two for recurrent $\mathrm{PTB}^{12}$ 21 ) are considered individually in the context of our current knowledge, we find that six studies are not amenable to clear interpretation, and three studies are supportive (see online supplementary table S1 and S2). Therefore, the inclusion of these six studies may have obscured a true association that our results support. Given the complexities of omega-3 biochemistry, perinatal physiology and the heterogeneity of baseline intakes, it is not surprising that limitations of these early trials have emerged as our knowledge has advanced. However, study designs are steadily improving, and more recent meta-analyses found significant effects of omega-3 in the prevention of PTB (<37 weeks) and early PTB ( $<34$ weeks). ${ }^{32} 69$

We still have some important things to learn before we can intervene effectively. For example, EPA and DHA are typically measured together in one category, as was the case in our study, and this has generally precluded the assessment of potentially distinct associations between these subcategories of LC omega-3 PUFA. In fact, the most recent Cochrane review mentions this as a future research need. ${ }^{69}$ Additionally, excess LC omega-3 PUFA supplementation in pregnancy may carry its own risks (eg, possible increases in postterm deliveries, artificial inductions or caesarean sections ${ }^{67}$ ), and these potential risks would need to be characterised before initiating any widespread interventions. Would changes in dietary norms share the same theoretical risks as high-dose prenatal supplementation? This approach would be in line with recent calls to recognise the importance of preconception health in determining pregnancy outcomes. ${ }^{70-73} \mathrm{~A}$ comparable situation may be the example of folic acid fortification to reduce the incidence of neural tube defects. ${ }^{74}$ Intake recommendations were relatively ineffective, but fortification strategies yielded positive effects. ${ }^{75}$
Finally, we note that we have assessed one part of a complex adaptive system. ${ }^{76}$ Even as the role of omega-3 intake in PTB prevention is solidified, the development of interventions will require transdisciplinary evaluation ${ }^{77}$ and iterative trials to identify strategies that minimise unintended consequences. For example, how can we obtain these fatty acids in a sustainable fashion without increasing exposure to the toxicants or teratogens that may be found in fish ${ }^{34}{ }^{78-80}$ Narrow interventions may fail where holistic approaches are needed. Thus, important hurdles remain, but this line of inquiry presents a valuable opportunity to design effective nutritional interventions for preventing PTB.

\section{CONCLUSIONS}

Our results provide a distinct line of evidence supporting the conclusion that sufficient omega-3 intake can reduce the risk of PTB. Furthermore, these findings provide a rough estimate of the impact of low omega-3 PUFA intake on PTB rates worldwide. These findings, in isolation, do not provide compelling evidence for a causal association between omega-3 intake and PTB. However, these results taken with previous findings from a variety of approaches indicate this association not only exists but is causal. ${ }^{8-23}$ 29-31 Therefore, we hypothesise that increasing omega-3 PUFA intake could decrease PTB rates in the 157 countries with estimated LC omega-3 PUFA levels less than $600 \mathrm{mg} /$ day. Although more work remains to be done in identifying safe sustainable strategies for delivering omega-3 fatty acids, this evidence provides justification for exploring appropriate nutritional strategies to reduce $\mathrm{PTB}$.

Contributors THC conceived of the primary study idea (based partly on prior work with SMW), conducted the analyses and drafted the manuscript. JB and SMW provided critical feedback and important analytic guidance, as well as key intellectual and writing contributions. SMW was the senior author and all authors approved the final version for submission.

Funding This work was supported in part by the March of Dimes Ohio Collaborative for the Prevention of Preterm Birth, and a National Institutes of Health grant P20 GM103534.

Disclaimer The funding sources had no involvement in the design or conduct of this research, the writing of the manuscript or the decision to submit it for publication.

The depiction of boundaries on the map(s) in this article do not imply the expression of any opinion whatsoever on the part of BMJ (or any member of its group) concerning the legal status of any country, territory, jurisdiction or area or of its authorities. The map(s) are provided without any warranty of any kind, either express or implied.

Competing interests None declared.

Patient consent for publication Not required.

Ethics approval This study combined and reanalysed two publically available datasets.

Provenance and peer review Not commissioned; externally peer reviewed.

Data sharing statement The study data are available in the supplement and additional data and details are available from the papers that we cited as data sources.

Open access This is an open access article distributed in accordance with the Creative Commons Attribution Non Commercial (CC BY-NC 4.0) license, which 
permits others to distribute, remix, adapt, build upon this work non-commercially, and license their derivative works on different terms, provided the original work is properly cited, appropriate credit is given, any changes made indicated, and the use is non-commercial. See: http://creativecommons.org/licenses/by-nc/4.0/.

\section{REFERENCES}

1. Blencowe H, Cousens S, Oestergaard MZ, et al. National, regional, and worldwide estimates of preterm birth rates in the year 2010 with time trends since 1990 for selected countries: a systematic analysis and implications. Lancet 2012;379:2162-72.

2. Institute of Medicine (US) Committee on Understanding Premature Birth and Assuring Healthy Outcomes: Preterm Birth: Causes, Consequences, and Prevention. Washington (DC: National Academies Press (US), 2007. http://www.ncbi.nlm.nih.gov/books/ NBK11362/.

3. Institute-of-Medicine, Committee-on-Understanding-PrematureBirth-and-Assuring-Healthy-Outcomes. Chapter 12: Societal Costs of Preterm Birth. In: Behrman RE, Butler AS, eds. Preterm Birth: Causes, Consequences, and Prevention. Washington (DC): National Academies Press (US), 2007.

4. Harrison MS, Goldenberg RL. Global burden of prematurity. Seminars in Fetal and Neonatal Medicine 2016;21:74-9.

5. Frey HA, Klebanoff MA. The epidemiology, etiology, and costs of preterm birth. Seminars in Fetal and Neonatal Medicine 2016;21:68-73.

6. Olsen SF, Joensen HD. High liveborn birth weights in the Faroes: a comparison between birth weights in the Faroes and in Denmark. Journal of Epidemiology \& Community Health 1985;39:27-32.

7. Olsen S, Sørensen TA, Secher N, et al. Intake of marine fat, rich in (n-3)-polyunsaturated fatty acids, may increase birthweight by prolonging gestation. The Lancet 1986;328:367-9.

8. Olsen SF, Secher NJ. A possible preventive effect of low-dose fish oil on early delivery and pre-eclampsia: Indications from a 50-year-old controlled trial. Br J Nutr 1990;64:599-609.

9. Olsen SF, Dalby Srensen J, Secher NJ, et al. Randomised controlled trial of effect of fish-oil supplementation on pregnancy duration. The Lancet 1992;339:1003-7.

10. Olsen SF, Grandjean P, Weihe P, et al. Frequency of seafood intake in pregnancy as a determinant of birth weight: evidence for a dose dependent relationship. Journal of Epidemiology \& Community Health 1993;47:436-40.

11. Baguma-Nibasheka M, Brenna JT, Nathanielsz PW. Delay of preterm delivery in sheep by omega-3 long-chain polyunsaturates. Biol Reprod 1999;60:698-701.

12. Olsen SF, Secher NJ, Tabor A, et al. Randomised clinical trials of fish oil supplementation in high risk pregnancies. Fish Oil Trials In Pregnancy (FOTIP) Team. BJOG 2000;107:382-95.

13. Helland IB, Saugstad OD, Smith $L$, et al. Similar effects on infants of $\mathrm{n}-3$ and $\mathrm{n}-6$ fatty acids supplementation to pregnant and lactating women. Pediatrics 2001;108:E82:e82.

14. Grandjean P, Bjerve KS, Weihe P, et al. Birthweight in a fishing community: significance of essential fatty acids and marine food contaminants. Int J Epidemiol 2001;30:1272-8.

15. Oken E, Kleinman KP, Olsen SF, et al. Associations of seafood and elongated $\mathrm{n}-3$ fatty acid intake with fetal growth and length of gestation: results from a US pregnancy cohort. Am J Epidemiol 2004;160:774-83.

16. Olafsdottir AS, Magnusardottir AR, Thorgeirsdottir $\mathrm{H}$, et al. Relationship between dietary intake of cod liver oil in early pregnancy and birthweight. BJOG 2005;112:424-9.

17. Szajewska H, Horvath A, Koletzko B. Effect of $n-3$ long-chain polyunsaturated fatty acid supplementation of women with low-risk pregnancies on pregnancy outcomes and growth measures at birth: a meta-analysis of randomized controlled trials. Am J Clin Nutr 2006;83:1337-44.

18. Makrides M, Duley L, Olsen SF. Cochrane Pregnancy and Childbirth Group. Marine oil, and other prostaglandin precursor, supplementation for pregnancy uncomplicated by pre-eclampsia or intrauterine growth restriction. Cochrane Database Syst Rev 2006;19:CD003402.

19. Horvath A, Koletzko B, Szajewska H. Effect of supplementation of women in high-risk pregnancies with long-chain polyunsaturated fatty acids on pregnancy outcomes and growth measures at birth: a meta-analysis of randomized controlled trials. Br J Nutr 2007;98:253-9.

20. Ramakrishnan U, Stein AD, Parra-Cabrera S, et al. Effects of docosahexaenoic acid supplementation during pregnancy on gestational age and size at birth: randomized, double-blind, placebo-controlled trial in Mexico. Food Nutr Bull 2010;31(2 Suppl):S108-S116

21. Harper M, Thom E, Klebanoff MA, et al. Omega-3 fatty acid supplementation to prevent recurrent preterm birth: a randomized controlled trial. Obstetrics and gynecology 2010;115(2 Pt 1):234-42.

22. Larqué $\mathrm{E}$, Gil-Sánchez A, Prieto-Sánchez MT, et al. Omega 3 fatty acids, gestation and pregnancy outcomes. Br J Nutr 2012;107 Suppl 2(S2):S77-S84.

23. Yamashita A, Kawana K, Tomio K, et al. Increased tissue levels of omega-3 polyunsaturated fatty acids prevents pathological preterm birth. Sci Rep 2013;3:3113.

24. Christian LM, Blair LM, Porter K, et al. Polyunsaturated Fatty Acid (PUFA) status in pregnant women: Associations with sleep quality, inflammation, and length of gestation. PLoS One 2016;11:e0148752.

25. Mohanty AF, Siscovick DS, Williams MA, et al. Periconceptional seafood intake and pregnancy complications. Public Health Nutr 2016;19:1795-803.

26. Le Donne M, Alibrandi A, Vita R, et al. Does eating oily fish improve gestational and neonatal outcomes? Findings from a Sicilian study. Women and Birth 2016;29:e50-e57.

27. Brantsæter AL, Englund-Ögge L, Haugen M, et al. Maternal intake of seafood and supplementary long chain $n-3$ poly-unsaturated fatty acids and preterm delivery. BMC Pregnancy Childbirth 2017;17:41.

28. Smid MC, Stuebe AM, Manuck TA, et al. Maternal obesity, fish intake, and recurrent spontaneous preterm birth. The Journal of Maternal-Fetal \& Neonatal Medicine 2018:1-7 (published Online First: 9 Feb 2018).

29. De Giuseppe R, Roggi C, Cena H. n-3 LC-PUFA supplementation: effects on infant and maternal outcomes. Eur $J$ Nutr 2014:53:1147-54.

30. Poniedzialek-Czajkowska E, Mierzynski R, Kimber-Trojnar Z, et al. Polyunsaturated fatty acids in pregnancy and metabolic syndrome: a review. Curr Pharm Biotechnol 2014;15:84-99.

31. Imhoff-Kunsch B, Briggs V, Goldenberg T, et al. Effect of $n-3$ long-chain polyunsaturated fatty acid intake during pregnancy on maternal, infant, and child health outcomes: a systematic review. Paediatr Perinat Epidemiol 2012;26 Suppl 1:91-107.

32. Kar S, Wong M, Rogozinska $\mathrm{E}$, et al. Effects of omega-3 fatty acids in prevention of early preterm delivery: a systematic review and metaanalysis of randomized studies. Eur J Obstet Gynecol Reprod Biol 2016;198:40-6.

33. Makrides M, Best K. Docosahexaenoic Acid and Preterm Birth. Annals of nutrition \& metabolism. 2016;69(Suppl 1):29-34.

34. Mahaffey KR, Sunderland EM, Chan HM, et al. Balancing the benefits of $n-3$ polyunsaturated fatty acids and the risks of methylmercury exposure from fish consumption. Nutr Rev 2011;69:493-508.

35. Klemens CM, Berman DR, Mozurkewich EL. The effect of perinatal omega-3 fatty acid supplementation on inflammatory markers and allergic diseases: a systematic review. BJOG 2011;118:916-25.

36. Shulkin M, Pimpin L, Bellinger D, et al. n-3 Fatty acid supplementation in mothers, preterm infants, and term infants and childhood psychomotor and visual development: A systematic review and meta-analysis. J Nutr 2018;148:409-18.

37. Micha R, Khatibzadeh S, Shi P, et al. Global, regional, and national consumption levels of dietary fats and oils in 1990 and 2010: a systematic analysis including 266 country-specific nutrition surveys. BMJ 2014;348:g2272.

38. Global, regional, and national consumption levels of dietary fats and oils in 1990 and 2010: a systematic analysis including 266 countryspecific nutrition surveys. BMJ 2015;350:h1702.

39. Lim SS, Vos T, Flaxman AD, et al. A comparative risk assessment of burden of disease and injury attributable to 67 risk factors and risk factor clusters in 21 regions, 1990-2010: a systematic analysis for the Global Burden of Disease Study 2010. The Lancet 2012;380:2224-60.

40. Micha R, Kalantarian S, Wirojratana P, et al. Estimating the global and regional burden of suboptimal nutrition on chronic disease: methods and inputs to the analysis. Eur J Clin Nutr 2012;66:119-29.

41. Burdge GC, Wootton SA. Conversion of alpha-linolenic acid to eicosapentaenoic, docosapentaenoic and docosahexaenoic acids in young women. Br J Nutr 2002;88:411-20.

42. Calder PC. Docosahexaenoic Acid. Annals of Nutrition and Metabolism 2016;69:8-21.

43. Olsen SF, Secher NJ. Low consumption of seafood in early pregnancy as a risk factor for preterm delivery: prospective cohort study. BMJ 2002;324:447-50.

44. Olsen SF, Halldorsson TI, Thorne-Lyman AL, et al. Plasma Concentrations of Long Chain N-3 Fatty Acids in Early and Mid-Pregnancy and Risk of Early Preterm Birth. EBioMedicine 2018;35:325-33. 
45. Wood SN. Package 'mgcv': GAMs with GCV/AIC/REML smoothness estimation and GAMMs by PQL. 2010 http://cran.r-project.org/web/ packages/mgcv/mgcv.pdf (Accessed 30 Oct 2011).

46. Craven P, Wahba G. Smoothing noisy data with spline functions - estimating the correct degree of smoothing by the method of generalized cross-validation Numerische Mathematik. 1979;31:377-403.

47. Zhang JY, Kothapalli KSD, Brenna JT. Desaturase and elongaselimiting endogenous long-chain polyunsaturated fatty acid biosynthesis. Curr Opin Clin Nutr Metab Care 2016;19:103-10.

48. Ameur A, Enroth S, Johansson A, et al. Genetic adaptation of fatty-acid metabolism: a human-specific haplotype increasing the biosynthesis of long-chain omega-3 and omega- 6 fatty acids. Am J Hum Genet 2012;90:809-20.

49. Innis SM. Omega-3 fatty acid biochemistry: perspectives from human nutrition. Mil Med 2014;179(11 Suppl):82-7.

50. Schmitz G, Ecker J. The opposing effects of $n-3$ and $n-6$ fatty acids. Prog Lipid Res 2008;47:147-55.

51. Howards PP. An overview of confounding. Part 2: how to identify it and special situations. Acta Obstet Gynecol Scand 2018;97:400-6.

52. Suttorp MM, Siegerink B, Jager KJ, et al. Graphical presentation of confounding in directed acyclic graphs. Nephrol Dial Transplant 2015;30:1418-23.

53. Bloomfield $\mathrm{FH}$. How is maternal nutrition related to preterm birth? Annu Rev Nutr 2011;31:235-61.

54. Zhou SJ, Best K, Gibson R, et al. Study protocol for a randomised controlled trial evaluating the effect of prenatal omega-3 LCPUFA supplementation to reduce the incidence of preterm birth: the ORIP trial. BMJ Open 2017;7:e018360.

55. Ferguson KK, O'Neill MS, Meeker JD. Environmental contaminant exposures and preterm birth: a comprehensive review. J Toxicol Environ Health B Crit Rev 2013;16:69-113.

56. Carlson SE, Colombo J, Gajewski BJ, et al. DHA supplementation and pregnancy outcomes. Am J Clin Nutr 2013;97:808-15.

57. Pearce N. The ecological fallacy strikes back. Journal of Epidemiology \& Community Health 2000;54:326-7.

58. Greenland S, Robins J. Invited commentary: ecologic studies-biases, misconceptions, and counterexamples. Am J Epidemiol 1994;139:747-60.

59. Morgenstern H. Ecologic studies in epidemiology: concepts, principles, and methods. Annu Rev Public Health 1995;16:61-81.

60. Ciesielski TH, Pendergrass SA, White MJ, et al. Diverse convergent evidence in the genetic analysis of complex disease: coordinating omic, informatic, and experimental evidence to better identify and validate risk factors. BioData Min 2014;7:10.

61. Saccone G, Berghella V. Omega-3 long chain polyunsaturated fatty acids to prevent preterm birth: a systematic review and metaanalysis. Obstetrics and gynecology 2015;125:663-72.

62. Saccone G, Berghella V. Omega-3 supplementation to prevent recurrent preterm birth: a systematic review and metaanalysis of randomized controlled trials. Am J Obstet Gynecol 2015;213:135-40.

63. Bulstra-Ramakers MT, Huisjes HJ, Visser GH. The effects of $3 \mathrm{~g}$ eicosapentaenoic acid daily on recurrence of intrauterine growth retardation and pregnancy induced hypertension. Br J Obstet Gynaecol 1995;102:123-6.
64. Onwude JL, Lilford RJ, Hjartardottir $\mathrm{H}$, et al. A randomised double blind placebo controlled trial of fish oil in high risk pregnancy. $\mathrm{Br} \mathrm{J}$ Obstet Gynaecol 1995;102:95-100.

65. Malcolm CA, McCulloch DL, Montgomery C, et al. Maternal docosahexaenoic acid supplementation during pregnancy and visual evoked potential development in term infants: a double blind, prospective, randomised trial. Arch Dis Child Fetal Neonatal Ed 2003;88:383F-90.

66. Tofail F, Kabir I, Hamadani JD, et al. Supplementation of fish-oil and soy-oil during pregnancy and psychomotor development of infants. $J$ Health Popul Nutr 2006;24:48-56.

67. Makrides M, Gibson RA, McPhee AJ, et al. Effect of DHA supplementation during pregnancy on maternal depression and neurodevelopment of young children: a randomized controlled trial. JAMA 2010;304:1675-83.

68. Escolano-Margarit MV, Ramos R, Beyer J, et al. Prenatal DHA status and neurological outcome in children at age 5.5 years are positively associated. J Nutr 2011;141:1216-23.

69. Middleton P, Gomersall JC, Gould JF, et al. Omega-3 fatty acid addition during pregnancy. Cochrane Database Syst Rev 2018;210:Cd003402.

70. Dunlop AL, Kramer MR, Hogue CJ, et al. Racial disparities in preterm birth: an overview of the potential role of nutrient deficiencies. Acta Obstet Gynecol Scand 2011;90:1332-41.

71. Stephenson J, Heslehurst N, Hall J, et al. Before the beginning: nutrition and lifestyle in the preconception period and its importance for future health. Lancet 2018;391:1830-41.

72. King JC. The risk of maternal nutritional depletion and poor outcomes increases in early or closely spaced pregnancies. J Nutr 2003;133:1732S-6.

73. Lu MC, Halfon N. Racial and ethnic disparities in birth outcomes: a life-course perspective. Matern Child Health J 2003;7:13-30.

74. Obican SG, Finnell RH, Mills JL, et al. Folic acid in early pregnancy: a public health success story. Faseb J 2010;24:4167-74.

75. Botto LD, Lisi A, Bower C, et al. Trends of selected malformations in relation to folic acid recommendations and fortification: an international assessment. Birth Defects Res A Clin Mol Teratol 2006;76:693-705.

76. Committee-on-a-Framework-for-Assessing-the-Health -E, -and-Social-Effects-of-the-Food-System; Food-and-NutritionBoard;-Board-on-Agriculture-and-Natural-Resources;-Institute-ofMedicine;- National-Research-Council. A Framework for Assessing Effects of the Food System. Washington (DC): National Academies Press, 2015.

77. Ciesielski TH, Aldrich MC, Marsit CJ, et al. Transdisciplinary approaches enhance the production of translational knowledge. Transl Res 2017;182:123-34.

78. Betts KS. Fish consumption caveat: advisories may not help with long-lived contaminants. Environ Health Perspect 2014;122:A57.

79. NOAA Fisheries Office of Sustainable Fisheries. http://www.nmfs noaa.gov/sfa/ (Accessed 24 Feb 2015).

80. U.S.D.A., National Agricultural Library, Sustainable Agriculture: Definitions and Terms. http://afsic.nal.usda.gov/sustainableagriculture-definitions-and-terms-1 accessed 2/24/2015 